\title{
Extubation time in neurosurgical patients: does it matter?
}

\author{
Tumul Chowdhury $\cdot$ Ronald B. Cappellani
}

Received: 23 October 2012/Accepted: 16 December 2012/Published online: 16 April 2013

(C) Japanese Society of Anesthesiologists 2013

To the Editor:

I read the article by Miura et al. [1] with great interest regarding the effect of propofol and isoflurane on brain tumor resection. They have meticulously described the methodology and the result. However, we want to address some important issues related to extubation time in this study.

First, in this study there was prolonged extubation time ( $>20 \mathrm{~min}$ ) in both groups. This finding is in contrast to usual practice even if we switch off the anesthetic agents at the end of the procedure [2,3]. Both anesthetic agents have shorter elimination half lives. More so, this practice does not seem to be acceptable in neurosurgical patients as they require rapid awakening for early neurological assessment. Second, nitrous oxide was used most commonly with the propofol group (Table 2), however, this group received significantly more fentanyl (Table 2). This finding is also conflicting as patients with nitrous oxide would have fewer requirements for opioids. More so, the concentration of nitrous oxide was not mentioned in the study nor could the time when it was stopped both be the contributing factors for prolonged extubation time in groups. Third, there were no data pertaining to BIS values after switching off the anesthetic agents. The BIS guided extubation is found to shorten the extubation time, so may influence the results of the present study [4]. Whether there were any additional opioids given and what method was adopted to prevent

An answer to this letter to the editor is available at doi:10.1007/s00540-013-1604-x.

T. Chowdhury $(\bowtie) \cdot$ R. B. Cappellani

Department of Anesthesiology, Health Sciences Center,

University of Manitoba, Winnipeg, Canada

e-mail: tumulthunder@gmail.com intraoperative awareness, were also not addressed. This relevant information perhaps could not be traced due to the retrospective nature of this study.

In conclusion, duration of extubation is important and can be detrimental in neurosurgical patients. It depends upon many factors including type of anesthetics, use of adjunct medications, metabolic factors, monitoring methods, core temperature and surgical factors. The prolonged intubation $(>20 \mathrm{~min})$ in cases of balanced anesthetic technique, especially in neurosurgical patients, warrant to rule out above mentioned factors.

\section{References}

1. Miura Y, Kamiya K, Kanazawa K, Okada M, Nakane M, Kumasaka A, Kawamae K. Superior recovery profiles of propofol-based regimen as compared to isoflurane-based regimen in patients undergoing craniotomy for primary brain tumor excision: a retrospective study. J Anesth. 2012;26:721-7.

2. Magni G, Baisi F, La Rosa I, Imperiale C, Fabbrini V, Pennacchiotti ML, Rosa G. No difference in emergence time and early cognitive function between sevoflurane-fentanyl and propofol-remifentanil in patients undergoing craniotomy for supratentorial intracranial surgery. J Neurosurg Anesthesiol. 2005;17:134-8.

3. Gauthier A, Girard F, Boudreault D, Ruel M, Todorov A. Sevoflurane provides faster recovery and postoperative neurological assessment than isoflurane in long-duration neurosurgical cases. Anesth Analg. 2002;95:1384-8.

4. Punjasawadwong Y, Boonjeungmonkol N, Phongchiewboon A. Bispectral index for improving anaesthetic delivery and postoperative recovery. Cochrane Database Syst Rev. 2007;4:CD003843. 